\title{
La conquista de Mauritania y el milagro de la lluvia del año 43 d. C.
}

SANTIAGO MONTERO HERRERO

La conquista de Mauritania por Roma ha sido en los últimos años objeto de diversos estudios (1), pero ninguno parece haberse detenido en un episodio, a mi juicio de interés desde el punto de vista militar y religioso. narrado por Dion Cassio.

En el año $43 \mathrm{~d}$. C. los moros, dirigidos por Salabos, fueron repetidas veces vencidos por el ejército romano de conquista mandado por Cn. Hosidio Geta por lo que decidieron buscar refugio en el desierto. El deseo de Geta de poner fin cuanto antes a las operaciones militares explica que se adentrase con la mayor parte de sus efectivos en el interior de la Mauritania. Pero llegados a algún punto al sur del Atlas, las tropas se vieron en una difícil situación a causa de la falta de agua. Fue entonces cuando un indígena aliado se ofreció a Geta a atraer, mediante ciertos ritos, el agua de la lluvia, lo que a menudo había conseguido ya para su pueblo. Mediente

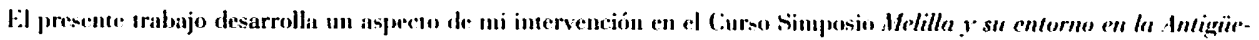
dad (Melilla 7-11 abril de 1997), tilulada -Rusaddir entre la Mauritania Tingiana y la Cesariense*. (unsirra rxpre-

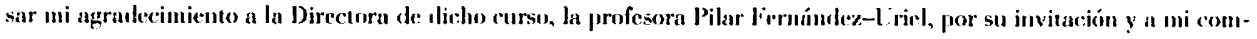
pañuro el profesor F. López Pardo por sus orientaciones hibliogrríficun. 
"cantos y encantamientos" mágicos logró una "lluvia milagrosa" que no sólo sació la sed de los romanos sino que persuadió a los moros, sus enemigos, a abandonar la lucha y a pedir la paz, convencidos de que los dioses estaban de parte de Roma.

La noticia es transmitida únicamente por Dion Cassio (LX, 9):

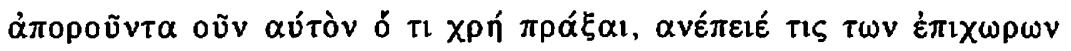

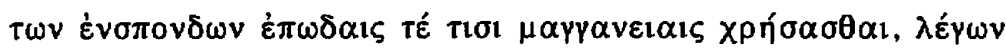

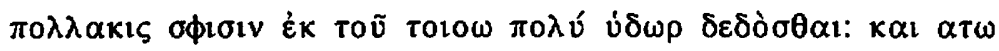

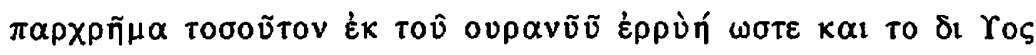

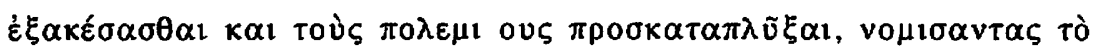

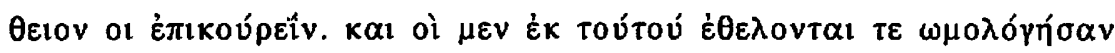

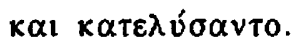

Teniendo en cuenta las características climáticas del norte de Africa (2) no sorprende que algunos pueblos o tribus hayan recurrido, al menos en casos de prolongada sequía, a ritos mágicos para la obtención de la lluvia. Hace años G. Charles-Picard escribía refiriéndose en general a las poblaciones libias: "Les eaux de pluie, comme les eaux souterraines possèdent une énergie sacrée. De là de nombreuses cérémonies magiques tendant à les susciter. Ces cérémonies ont été observées à l'époque contemporaine par les ethnographes" (3).

Sabemos por las fuentes greco-latinas que algunos de ellos, como los marmáridas, los garamantes o los masilios tenían especiales poderes en el ámbito mágico (4), si bien ninguno conocido sobre los vientos y las nubes. Sin embargo, por razones que iré examinando, me inclino a identificar al aliado de Roma con el pueblo psilo (5), famoso por sus prácticas mágicas. Los psilos colaboraban ya con el ejército romano de Catón en el año 49-48 a. C., cuando aquél atravesó el árido desierto de la Cirenaica:

“marchó por tierra en la estación del invierno... y llevando además mucho botín, carros y los que se llamaban psilos, que curaban las mor- 
deduras de las serpientes, chupando con la boca el veneno, y que amortiguaban y adormecían a las mismas serpientes con encantamientos" (Plut., Cat. 56).

Es cierto que los psilos eran conocidos en época romana por sus poderes sobre las serpientes y escorpiones y su capacidad para curar las mordeduras venenosas. Pero desde mucho antes circulaban noticias y leyendas sobre la acción imprecatoria de los psilos contra los agentes atmosféricos; éstas eran muy antiguas pues ya Heródoto se refiere a ellas:

\footnotetext{
"Vecinos a los nasamones son los psilos. Estos han desaparecido del siguiente modo: el noto, viento que les soplaba, secaba sus depósitos de sus aguas, y toda su región — que se hallaba en el interior de la Sirteestaba seca; ellos, tras haberlo decidido de común acuerdo, emprendieron una expedición militar contra el noto (digo lo que dicen los libios) y cuando se hallaban en el desierto, poniéndose a soplar el noto los sepultó en la arena" (IV, 173).
}

Observemos pues que el historiador griego se hace eco, en realidad, de una leyenda que circulaba sobre los psilos entre las poblaciones del norte de Africa según la cual, los psilos, deciden actuar — quizá no mediante una "expedición militar" como afirma Heródoto, sino mediante técnicas mágicas - contra el viento que impide la lluvia. Los dioses, indignados por esta desafiante actitud de impiedad, deciden castigar a los psilos con su extermininio.

Del pasaje de Heródoto se desprende que los vientos eran concebidos entre las poblaciones norteafricanas como una fuerza divina. Recientemente algunos autores modernos han señalado la pervivencia de este tipo de concepciones en los beréberes (6).

Pomponio Mela señala que en la provincia de la Girenaica - y; por tanto, de nuevo en el territorio de los psilos- existía una roca consagrada al Austro que cuando era tocada por la mano del hombre agitaba este viento en tempestad y levantaba olas de arena como si fuera el mar: 
Inde ad Catabathmon Cyrenaica est, in eaque sunt inclitae... et rupes quaedam austro sacra. Haec cum hominum manu attingitur ille inmodicus exsurgit harenasque quasi maria agers sic serevit ut fluctibus (Chor. I, 8, 39).

Plinio (NH II, 115), posiblemente siguiendo a este último autor, recoge casi textualmente la noticia pero añade un detalle: es impío tocar con la mano la roca consagrada al viento Austro: rupes quaedam austro traditur sacra, quam profanum sit attrectari hominis manu, confestim ausiro velvente harenas.

Sin embargo, el pueblo o la tribu de los psilos, pese a lo que creía Heródoto, no desapareció (quizá como ethnos, pero no como genos). En el siglo I d. C. el propio Plinio los vio personalmente (NH XXV, 123: vidimusque Psyllos; cfr. VII, 14), siendo mencionados por numerosos autores greco-latinos al menos hasta el siglo III d. C. Aún más, es sólo a partir de la época de Calias (que en la primera mitad del s. III a. C. vive en la corte del tirano Agatocles de Sicilia), cuando los psilos comienzan a ser asociados como encantadores de serpientes.

Pero posiblemente sus poderes para atraer o rechazar ciertos vientos ( $\mathrm{y}$ con ellos las lluvias), nunca llegaron a perderse del todo. Un autor latino, Aulo Gelio, siguiendo a Heródoto, contribuía a divulgar la noticia aún en el siglo II d. C.

"Los Psilos habitaron en otro tiempo en Africa y fueron vecinos de los Nasamones. Habiendo en una época soplado con violencia el Austro en su país durante muchos días, se secaron los manantiales. Careciendo de agua los Psilos, se irritaron contra el Austro y decidieron empunar las armas para ir a pedirle cuenta como a enemigo por la injusticia que les había hecho. Enseguida partieron; el Austro salió a su encuentro con una legión de vientos, y la nación entera, con sus tropas y sus armas, quedó sepultada bajo montañas de arena. Habiendo perecido todos los Psilos hasta el último, ocuparon su país los Nasamones" (7). 
Por tanto la leyenda de que los psilos lucharon contra el Austro, viento que sopla de la parte del sur, es decir, del desierto, fue conocida primero por las tribus norteafricanas y los geógrafos griegos y, posteriormente, por los romanos cuando a finales de la República los incorporaron a su ejército.

Esta acción de los psilos sobre los vientos de las Sirtes (antiguos dos golfos de la costa de Túnez y Trípoli) responde a una necesidad: los vientos de esta zona eran temibles aún en época romana porque hacían encallar las embarcaciones, como Virgilio recuerda con detalle en su Eneida (I, 108ss.). Por la misma razón, Horacio (Epod. IX 31) dice de las Sirtes que son siempre juguetes del Noto: exercitatas aut petit Syrtis Noto; Ovidio (Am. II, 16, 22-23) proclama que yendo con su amante se atrevería "a atravesar las Sirtes líbicas y a entregar mis velas a los Notos intempestivos"; y Propercio (II, 9, 33-34) asegura que ni los variables vientos de las Sirtes cambian tanto como las mujeres (Non sic incerto mutantur flamine Syrtes...). Pero el pasaje más completo (cronológicamente anterior a todos éstos), es de Salustio quien llega a hacer depender la configuración geográfica de las dos Sirtes de la acción de los vientos:

"La parte de ellos próxima a tierra es muy profunda: el resto, al azar, profundo en parte y en parte vadoso, según los temporales; porque cuando empieza el mar a engrosar y a enfurecerse con los vientos, las olas arrastran allí légamo, arena y grandes bloques de piedra; así cambia con los aires el aspecto de aquellos lugares, y por este arrastre, se llamaron Sirtes" (Bellum Yugurt. 78, 2-3).

El Austro es en las Sirtes el peor de los vientos al azotar a las poblaciones del interior $\mathrm{y}$ hacer peligar la navegación; Lucano, se refiere al "Austro borrascoso" que barre impetuosamente desde las Sirtes líbicas el mar inmenso (Fars., I, 498-499: cum turbidus Auster reppulit a Libycis inmensum Syrtibus aequor...). Más adelante vuelve a insistir en el Austro como peligro para las embarcaciones: 
“'.. rugió el Austro ensombrecido con denso aguacero (densis fremuit niger imbribus Auster). Enfurecido contra sus propios dominios, protegió con una tromba las aguas en que se habían adentrado los navíos, rechazó las olas dentro de las Sirtes y cortó el mar con bancos de arena" (Fars., IX, 320-323).

Los psilos, fueron conocidos pues, primero como dominadores de los vientos y la lluvia y, después como encantadores de serpientes y hábiles curadores de picaduras venenosas. No faltan sin embargo conexiones entre la lluvia y las serpientes. H. Treidler, que no cita el pasaje de Dion Cassio, afirma en su excelente trabajo sobre los Psilos: "Bei primitiven Menschen war bisweilen die Schlange das Sinnbild des Regens, der Vermittler zwischen den Regen und den Regengöttern (8). Más adelante, vuelve a insistir en la vinculación de la lluvia y la serpiente: "Auch die Psylloi, die unter gleichen kümmerlichen Verhältnissen wohnten, hatten allen Anlass, sich die Gunst der Regengötter zu erhalten, und so mag die Schlange bei ihnen ebenfalls als Symbol des Regens ihre ursprüngliche Bedeutung gehabt haben" (9).

Los lapidarios mágicos también establecían este tipo de conexión. El Liber lapidum, conocido como Damigeron-Evax, recuerda que entre las propiedades de la piedra elitropia, que "nace en Libia" figura, convenientemente consagrada, tanto la de "oscurecer el aire con truenos y relámpagos y lluvias y tempestades" y "provocar la lluvia" como inmunizar "contra todo veneno" (Damig. Evax., 2).

Por último, el episodio narrado por Dion Cassio, podemos considerarlo un precedente de otra "lluvia milagrosa", si bien ésta mucho más célebre: la que se produjo en el año 172 d. C., bajo el reinado de Marco Aurelio (10). El ejército romano (la legión XII Fulminata), aislado en las montañas de Panonia y cercado por los cuados, agobiado por el calor sofocante y la falta de agua, se vio, de repente, sorprendido por una oportuna tormenta acompañada de lluvias abundantes que permitió a los romanos reponerse y rechazar a los bárbaros. El relato es transmitido también por el propio Dión Cassio (11), si bien sorprendentemente ninguno de los muchos estudiosos que se refieren a él alude al episodio mauritano del $43 \mathrm{~d}$. C. 
El milagro fue atribuido a Arnufis, sacerdote (hierogrammateys) de Isis, que por entonces pertenecía al séquito imperial de Marco Aurelio (synonta to Marco dice el historiador griego). Sus "artes ocultas" (sophía tiní) lograron la intervención de Hermes Aérios (Thot, el dios de la magia al que por entonces también se asimiló el Mercurio latino) (12).

No obstante la autoría del "milagro de la lluvia" también fue atribuído a las plegarias de otros personajes como Juliano el Teurgo, muy conocido en aquél tiempo, hijo de un famoso mago (Juliano el Caldeo) que vivió en época de Domiciano (13), a las invocaciones a Júpiter Tonante de propios soldados romanos (14) e incluso a la presencia de los cristianos (15). Pese a todo, las recientes contribuciones (Guey, Posener) se inclinan a aceptar la historicidad de la "versión egipcia" frente a todas las demás.

Los paralelos entre ambos episodios son evidentes: a) es el ejército romano quien atravesando graves dificultades en territorio enemigo se ve agobiado por la sed; b) un "aliado" africano al servicio de los romanos, actuando mediante técnicas mágicas evoca la lluvia; c) el milagro permite a los militares romanos ganar la guerra. 
1 M.C. Sigman, The Role of the indigenous Tribes in the Roman occupation of Mauritania Tingitana, Now York, 1976: Id., "The Romans and the indigenous tribes of Mauritania Tingitana", ITistoria 26, 1977, 415-439; E. Frezouls, "Rome et la Maurétanis 'Tingitane: un conslat d'échec?", Antiquités Africaines 18, 1980, 65-93; F. l.ópez Pardo, "Mauritania Tingitana: de mercado colonial púnico a provincia periférica romana", Madrid (tesis doctoral), 1987; E. Cozalbes Gravioto, La ciudad antigua de Rusadis: Aportaciones a la Iistoria de Melilla en la Antigüedad, Melilla, 1991. El úlcimo trabajo publicado sobre el tema, también de este último autor, es: "El ejército romano de ocupación en Mauritania T'ingitana en el siglo l", $H A m$ ' 20, 1996. 253-272.

La bibliografía sobre la romanización del norte de Africa ha sido recogida y comentada por E. Gozalbes, " $\wedge$ gunas notas acerca de la bibliografía sobre la resistencia a la romanización en el norte de Africa". Tempus 7, 1994, 33-43.

2 Sobre el clima del norte de Afriea y los posibles cambios climáticos, efr.: E.F. Gautier, Le pasée de lAfrique du Nord. Paris, 1937. E. Le Roy, "Ilistoire et clima". Amales E.S.C. 14, 1954, 3-34.

3 G. Charles-Picard, Les Religions de IAfrique Antique, Paris, 1954, p. 10.

4 Sobre prácticas mágicas entre los pueblos norteafricanos, c:fr. R. Seguin, "Lat magie dans l'A frique romaine", en Magie et lithéralure, Paris, 1989, 32-44; S. Montero, "La magia mell'Africa Romana: pluralità di tecniche e diversità geogralica", en Alti del Congresso internazionale di studi sn "Multilinguismo e pluriculluralismo nel Maghreb arabo e berberm: passato e presente (Amalfi 3-6 maggio 1995) (en prensa).

5 Cfr. J. Desanges, Catalogue des tribus africaines de l'Antiquité classique à l'ouest du
Nil, Dakar, 1962. pp: 155-156. Para la geografía de esta zona es fundamental el trabajo de A. Mastino, "I Je Sirte negli scrittori di ctà augustea", en LAfrique dans l'Occident Romain, Paris-Roma, 1990, 15-48.

No faltan alusiones a contactos entre los territorios de los psilos y el de lus mauros y así Horacio (Carm., II, 6 3-4) escribe: et barbaras Syrtis, ubi Maura semper aestuat unda...

6 G. Camps, Berbères. Aux marges de l'histoire, Toulouse, 1982.

J. Desanges, Pline l'Ancien, Histoire Naturelle V, 1-46, Paris, C.LJ.F., 1980 hace observar que el folklore beréber conserva creencias concernientes al viento del sur.

7 N.A. XV1, 11, 3-8: ... in quarto deniqme Herodoti libro frabulosam de Psyllis hac inrenimus: Psyllos quondam fuisse in term Africa conterminos Nasromonibus Atustrummue in finibus corum quodam in compore perquam validum ac diutimum favisse; co flatu alyuam ommem in locis, in quibus coleban, exaruisse; Psyllos re aquarin defectos eam iniuriam grasiter Austro suscensuisse decreumque fecisse, ui armis sumptis al Alusirum proinde quasi ad hostem iure belli res petitum proficisecrentur. Alque ita profectis centum Alustrum magno spiritus agmine venisse obriam eosque universos cum ommibus copiis armisque cumulis montibusque harenarum supermectis operuisse. Eo facto Psyllos ad umum omnis interisse, itaque corum fines a Nasramonilus occupatos.

8 RE, s.u.Psylloi col.1472.

9 RE, s.r.Psylloi col.1472

10 La bibliogralía sobre la lluvia milagrosa del 172 d. C. es muy abundante: $\Lambda$. Calderini, "L'iscrizione aquileiense di larnouphis", Aquileia Nostra 8-9, 1937-1939, 67-72; J. Guey, "La date de la pluie miraculeuse (172 après J.C.) et la coloune Aurélienne I et II", MEFR 60, 1948, 105-127: 61, 1948, 3-118: 
Id.. "Encore la "pluie miraculeuse". RPh 22. 19+8, 16-62; M. Sordi, "Le monete di Marco Aurelio e la pioggia miracolosa" Ann./st.Itrel.Numism, 5-6, 1958-1959, 41-55; W. Jobst, "11 Juni 172 n. Clir. Der Tag des Blitz- und Regenwunders im Quadenlande" $S A W / 2335.1978 .36$ : Z. Rubin, "Weather miracles under Marens Aurelius", Alhenoeum 57, 1979, 357-380: G. Fuwden, "Pagan Versions of llee Rain Miracle of A.D. 172", Historiu 36, 1987. 83-95; A. Birley. Marcus Aurelius, London. 1987, 22?. 251-259 passim.

11 Dion Cass. 71, 8, +

12 Durmute las excavaciones del pretorio imperial de Aquileya (levantado en el invienu del 168-169 d. (:) fue hallada una dedicación de Arnufis a lsis (Dea Lipiphane) que parece probar la historicidad del personaje. Un pasaje de la Kistoria Augusta (Vit.MA 13, 1-3) alude a quee antes de este episodio, el emperador Marco Aurclio convocó sacerdotes de todas partes del Imperio para ejecutar "ritos extranjeros" (peregrini) de profilaxis colectiva con motivo de una pestilentia; el mago egipcio pudo haber participado en dicho ritual, ya que un fragmento de Eliano atestigna entre las especialidades de los hierogrommateis ritos purificatorios contra las cpidemias. Poco después. en el 167 d. (... delió pasar a formar parte del séquito del cjército romano.

13 Anast. Qunestiones et responsiones centum quinquaginte quattor: $\mathrm{Q} . \mathrm{XX}=\mathrm{PC} ; 89$, coll. 524-525. Se le menciona en algunas fuentes como rival de Apuleyo y Apolonio de Tiana en la purificación de Roma durante una pestilencia.
14 Las fuentes oficiales, de lats que la escena XVI de la columna de Marco Aurelio (erigida hacia el $176 \mathrm{~d}$. C.) asi comm un medallón romano del 173 (Gnechi, I medaglioni romani. II, p. 28, tav. 60) 1) atribuyeron el prodigio - dentro de la más estricta ortodoxia romana- a lat intervención de Jujpiter Tonante yue, con sus rayos detuvo a los bárbaros. En el siglo IV d. C. el poeta Clandiano, aún conoriendo la atribución del milagro a Julianu el Teńrgo, se inclina tumbién por la "versión oficial" romana (I)e II cons. Hon.. 340-350) rechazando la posibilidad de que hubieran sido las "fómunlas cakdeas". En un paisaje de sus Meditaciones ( $V, 7)$ ) el propio Marco Aurelio arribuye un milagro do. caracteristicas similares a éste a la plegaria simple y libre dirigida por los atenienses al amigo Zeus, lo cue parece reforzar la lipótesis de clue adscribiese el prodigio danubiano a has plegarias de suls legiones.

15 Tertul. Apol. 5. 6; ad Scapulam 4. 7-8; Eus. HEV, 1-6: Oros. VIl. 15, 9-11: Aria Sanctorum, lita lbercii, p. 485,s. Nissen. La legio XII Fulminata (asi llamaula descle el siglo I) era originaria de Melitene, una de las ciudades más cristianizadas do Asia Menor y fue precisamente - según dichas fucoutesla plegaria de los soldados cristianos (precationibus militum) la que logró que Dios obrara el milagro. Una pretendida carta oficial del emperador Marco Aurelio al Semado (autentien según M. Sordi) es argumentada por las luentes cristianats como prueba. De hereloo, en la escena XVI de la columna de Mareo Aurelio se representa a un soldado con los brazos y la mirada dirigides hacia el cielo. 